\title{
Evaluating Forest Waste on Adsorption of Cd(II) from Aqueous Solution: Equilibrium and Thermodynamic Studies
}

\author{
Handan Ucun Özel ${ }^{1}$, Betül Tuba Gemici ${ }^{1 *}$, Halil Barış Özel², Ercan Berberler ${ }^{1}$ \\ ${ }^{1}$ Bartin University, Faculty of Engineering, Department of Environmental Engineering, \\ Kutlubey Campus, Bartin, Turkey \\ ${ }^{2}$ Bartin University, Faculty of Forestry, Department of Forest Engineering, \\ Agdaci Campus, Bartin, Turkey
}

Received: 13 July 2018

Accepted: 7 October 2018

\begin{abstract}
The aim of this work was to investigate the adsorption potential of Uludag fir (Abies nordmanniana subsp. bornmülleriana Mattf.) on cadmium removal using batch experiments. The effect of parameters such as initial metal concentration, initial $\mathrm{pH}$, biosorbent dosage, stirring speed, contact time and temperature was examined. The Langmuir and Freundlich models were applied to describe the equilibrium isotherms, and the biosorption process followed the Langmuir adsorption isotherms model with high coefficients of correlation at different temperatures. The kinetics of the sorption were analysed using the pseudo first-order and pseudo second-order kinetic models. The pseudo second-order kinetic model fit well in correlation with the experimental results. Moreover, the evaluated thermodynamic parameters $\left(\Delta \mathrm{G}^{0}, \Delta \mathrm{H}^{0}, \Delta \mathrm{S}^{0}\right)$ showed that the sorption process was feasible, spontaneous and endothermic in nature. This study showed that Uludag fir (Abies nordmanniana subsp. bornmülleriana Mattf.) can be used as an effective and ecologically friendly biosorbent for removal of $\mathrm{Cd}(\mathrm{II})$ from aqueous solutions.
\end{abstract}

Keywords: adsorption, cadmium, Uludag fir (Abies nordmanniana subsp. bornmülleriana Mattf.), isotherms, kinetics

\section{Introduction}

The release of heavy metals to the environment due to industrialization and urbanization creates significant environmental pollution [1]. Heavy metals have direct toxic effects on living organisms unless there is a permanent dilution and sedimentation. Among the heavy metals, cadmium is one of the

*e-mail: btakcay@bartin.edu.tr most widespread pollutants in the environment and is frequently released from various industries such as electroplating, metallurgy, phosphate fertilizers, pigments, nuclear, Ni-Cd batteries and other uses [2]. Cadmium usually is present as a divalent cation, $\mathrm{Cd}(\mathrm{II})$, and has high solubility in water in this form. Because it is not biodegradable in the environment, $\mathrm{Cd}(\mathrm{II})$ can easily be transported from one medium to another and eventually is enriched by bioaccumulation in the ecosystem [3]. Cd(II) enters into humans and other living organisms through contaminated water and the food chain, and can cause irreversible damage [4]. This 
Cd(II) pollution can lead to serious illnesses such as kidney damage, renal disorder, human carcinogen, and high blood pressure $[5,6]$. For this reason, the use of an effective and economical method for removing $\mathrm{Cd}(\mathrm{II})$ from aquatic systems is an important issue for human health and the ecosystem [7].

Today, several techniques are applied to remove heavy metal contamination, such as chemical precipitation, reverse osmosis, membrane separation, ion-exchange methods and the biosorption process. Among these methods, the most economical and efficient process is biosorption process. Also, it is significantly necessary to develop alternative inorganic or organic sorbents that are inexpensive and abundant in the environment for removing heavy metals in biosorption processes. The search for cheap sorbents in biosorption applications has led to the search for the ability of forest and agricultural wastes to remove heavy metal ions. There are several studies on heavy metal removal using forest and agricultural waste such as bark from pinuspinaster [8]; sawdust of beech, linden and poplar trees [9]; pine cone powder [10]; castor seed hull [11]; cashew nut shell [12]; wheat straw [13]; bark, chestnut bur, sawdust, pinecone, pine needle and pinenut cone [14]; and Pinus sylvestris L. [15].

In this study, Uludag fir (Abies nordmanniana subsp. bornmülleriana Mattf.) of forest waste was evaluated as a biosorbent for removing $\mathrm{Cd}$ (II) from aqueous solution using the batch sorption technique. The effect of parameters, including initial metal concentration, initial $\mathrm{pH}$, biosorbent dosage, stirring speed, temperature and contact time were studied. Two isotherm models (Langmuir and Freundlich) were applied to describe the distribution of metal ions between the liquid phase and the solid phase at constant temperature. Moreover, kinetic (pseudo first-order and pseudo second-order) and thermodynamic $\left(\Delta \mathrm{G}^{0}, \Delta \mathrm{H}^{0}, \Delta \mathrm{S}^{0}\right)$ behaviors of the $\mathrm{Cd}(\mathrm{II})$ ions onto Uludag fir were carried out to get information about adsorption studies.

\section{Material and Methods}

\section{Chemicals}

All purchased chemicals were analytical grade provided by Sigma Aldrich. Cd(II) solutions were prepared from the $\mathrm{CdCl}_{2}$ salt in analytical purity. A standard stock $\mathrm{Cd}(\mathrm{II})$ solution was prepared at a concentration of $250 \mathrm{mg} / \mathrm{L}$ and desired concentrations (5-50 $\mathrm{mg} / \mathrm{L})$ of cadmium were prepared by making various dilutions using stock solution with distilled water. The $\mathrm{pH}$ was adjusted using diluted $0.1 \mathrm{M} \mathrm{HCl}$ and $0.1 \mathrm{M} \mathrm{NaOH}$ solution.

\section{Preparation of Biosorbent}

Uludag fir (Abies nordmanniana subsp. bornmülleriana Mattf.) was selected in these experiments as a biosorbent and obtained from Bartin, Turkey. This material was washed with distilled water and dried at $80^{\circ} \mathrm{C}$ for 24 hours. The dried biomass was ground and sieved through a $0.5-1 \mathrm{~mm}$ particle size.

\section{Experimental Apparatus}

Biosorption experiments were carried out in 250-mL Erlenmeyer flasks using $100 \mathrm{~mL}(25 \mathrm{mg} / \mathrm{L})$ metal-bearing solution with $5 \mathrm{~g} / \mathrm{L}$ of the dried adsorbents. The sample was stirred for $180 \mathrm{~min}$. using an orbital shaker (Jeio Tech IST-4075R) at a constant stirring speed of $150 \mathrm{rpm}$. After the adsorption process, the solution was centrifuged for $5000 \mathrm{rpm}$ using a Nüve NF200 centrifuge. The concentrations of Cd(II) in the solutions before and after adsorption were determined by a Shimadzu AA7000 atomic adsorption spectrophotometer.

\section{Results and Discussion}

\section{Effect of Initial Metal Concentrations}

The effect of initial $\mathrm{Cd}(\mathrm{II})$ concentrations onto adsorption performance in the range of $5 \mathrm{mg} / \mathrm{L}$ to $50 \mathrm{mg} / \mathrm{L}$ was studied. The results are shown in Fig. 1. It has been seen that the removal efficiency of $\mathrm{Cd}$ (II) decreased as the initial concentration was increased and the maximum initial metal concentration was found to be $5 \mathrm{mg} / \mathrm{L}$ (93.6\%). Moreover, adsorption capacity increased from $0.94 \mathrm{mg} / \mathrm{g}$ to $5.79 \mathrm{mg} / \mathrm{g}$ while the initial Cd concentration was increased from $5 \mathrm{mg} / \mathrm{L}$ to $50 \mathrm{mg} / \mathrm{L}$. As the concentration of Cd (II) increases, the driving force increases, and the diffusion of $\mathrm{Cd}(\mathrm{II})$ ions from the solution to the adsorbent surface accelerates. Moreover, adsorption efficiency decreased with increasing initial concentration because of the lack of active binding sites. It is easier to bind the $\mathrm{Cd}(\mathrm{II})$ ions to the biosorbent at low initial concentrations because there is sufficient binding area for the metal ions.

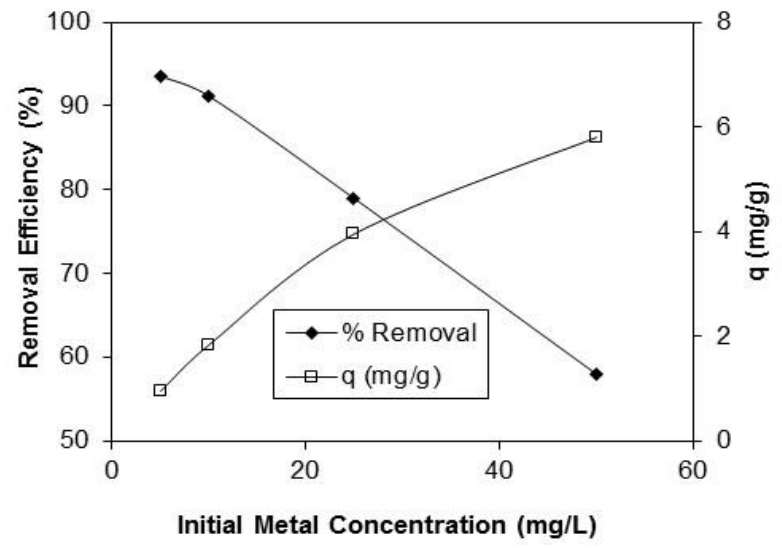

Fig. 1. Effect of initial Cd(II) concentrations. 


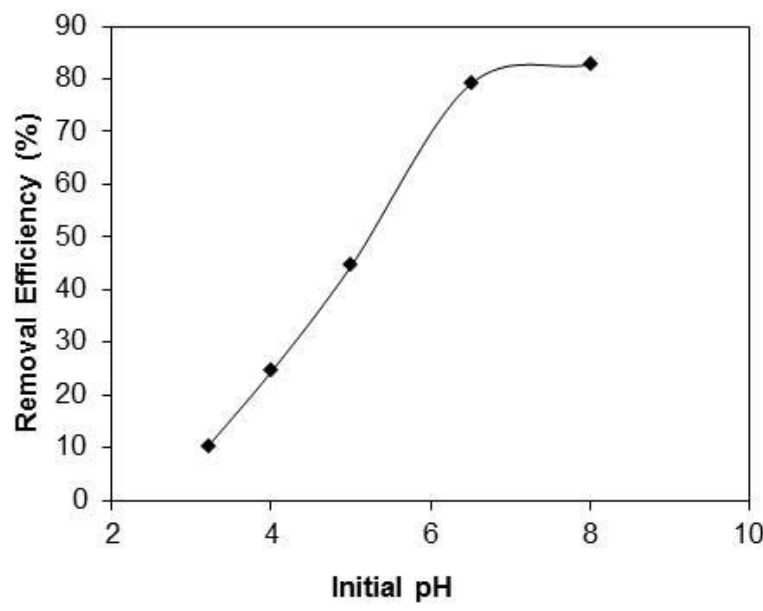

Fig. 2. Effect of initial $\mathrm{pH}$.

\section{Effect of Initial $\mathrm{pH}$}

The $\mathrm{pH}$ of the medium is an important parameter because hydrogen and hydroxyl ions may strongly affect the biosorption mechanism, such as the type of metal ions and the surface properties of the adsorbent. Thus, adsorption performance is significantly influenced by the initial $\mathrm{pH}$ for removal of metal ions. In this study, the effect of initial $\mathrm{pH}$ at 3.2-8.0 on $\mathrm{Cd}$ (II) removal was investigated and the results are presented in Fig. 2. The adsorption efficiency increased from $10.1 \%$ to $78.9 \%$ with the increase of $\mathrm{pH}$ from 3.2 to 6.5. Adsorption efficiency changed very little in $\mathrm{pH}$ range of 6.5-8.0. According to the results, hydrogen ions and metal ions are in competition, which leads to reduced efficiency at low $\mathrm{pH}$ values. As the $\mathrm{pH}$ value increases, the hydrogen ion concentration in the solution decreases and the negative charge on the adsorbent surface increases. This positively affects the adsorption of Cd(II) ions and increases adsorption efficiency [16]. The optimum $\mathrm{pH}$ value was found to be 6.5 and this $\mathrm{pH}$ value was used in subsequent studies.

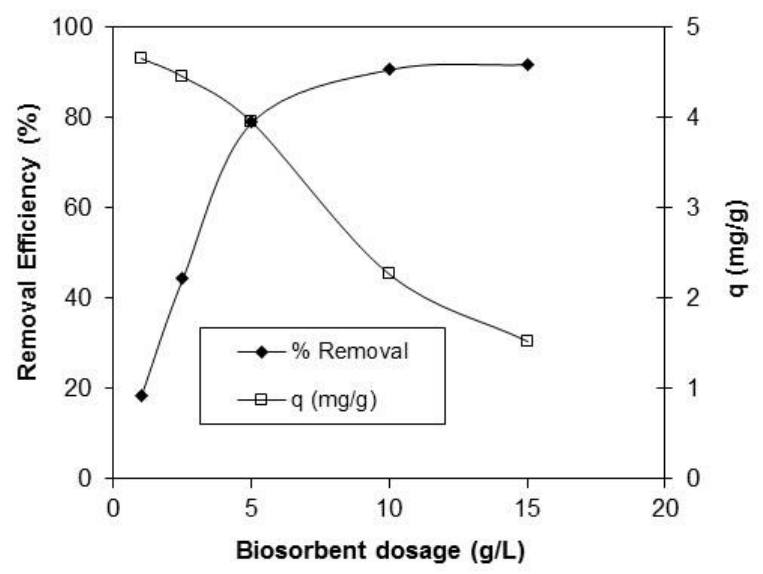

Fig. 3. Effect of biosorbent dosage.

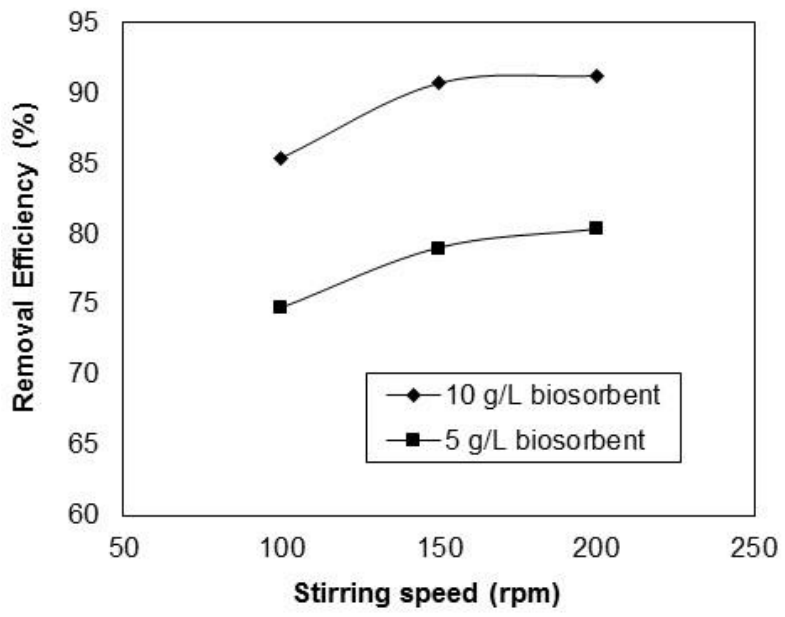

Fig. 4. Effect of stirring speed.

\section{Effect of Biosorbent Dosage}

The effect of biosorbent dosage was investigated in the range of $1-15 \mathrm{~g} / \mathrm{L}$ and the results are presented in Fig. 3. The removal efficiency of $\mathrm{Cd}$ (II) increased from $18.6 \%$ to $91.8 \%$ as the biosorbent dosage was increased from $1 \mathrm{~g} / \mathrm{L}$ to $15 \mathrm{~g} / \mathrm{L}$. According to the results, when the biosorbent dosage is increased from $1 \mathrm{~g} / 1$ to $10 \mathrm{~g} / \mathrm{L}$, the adsorption efficiency is increased rapidly. Moreover, there was no significant change in removal efficiency at 10 and $15 \mathrm{~g} / \mathrm{L}$ biosorbent dosage. When the adsorbent dosage increases, the biosorbent surface area and suitable active binding sites for binding of the $\mathrm{Cd}(\mathrm{II})$ ions to the surface of biosorbent are increased, resulting in increased adsorption efficiency.

\section{Effect of Stirring Speed}

The effect of stirring speed was studied in the range of 100-200 rpm at 5 and $10 \mathrm{~g} / \mathrm{L}$ and the results are shown in Fig. 4. According to the result, as the stirring speed increased from 100 to $200 \mathrm{rpm}$, removal efficiency of $\mathrm{Cd}(\mathrm{II})$ increased from $74.7 \%$ to $80.3 \%$ at $5 \mathrm{~g} / \mathrm{L}$ and from $85.3 \%$ to $91.2 \%$ at $10 \mathrm{~g} / \mathrm{L}$. As seen from the results, stirring speed did not significantly affect removal efficiency - especially when the mixing speed was increased to $150 \mathrm{rpm}$ or $200 \mathrm{rpm}$.

\section{Effects of Temperature and Contact Time}

In this study, the effect of temperature was investigated in the range of $15-45^{\circ} \mathrm{C}$ and the results are presented in Fig. 5. According to the obtained data, as the temperature increased from $15^{\circ} \mathrm{C}$ to $45^{\circ} \mathrm{C}$, removal efficiency increased, but there was not much change in adsorption efficiency. Higher temperatures generally increase biosorption performance due to increased surface activity and kinetic energy of the solute [17]. The increase in surface activity suggests 


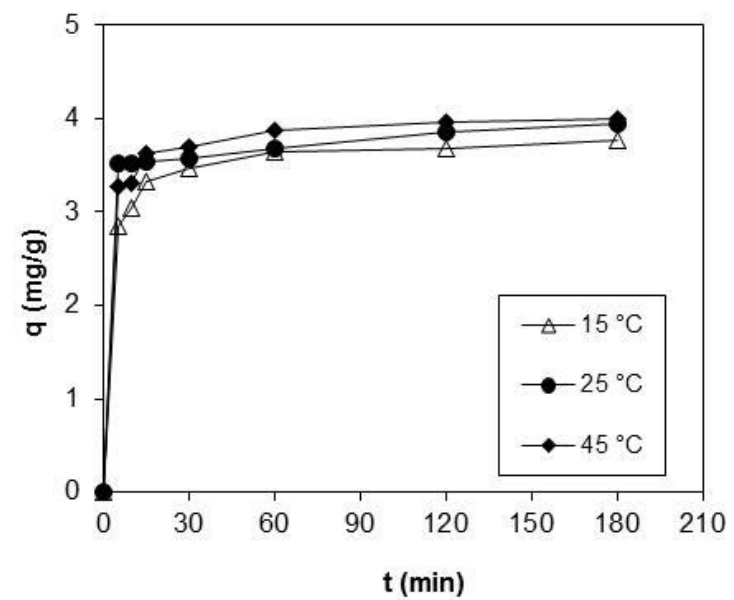

Fig. 5. Effect of temperature and contact time.

that the adsorption between $\mathrm{Cd}(\mathrm{II})$ and Uludag fir is endothermic. In addition, when the contact time is examined, it was observed that from Fig. 5, the adsorption of $\mathrm{Cd}$ is very fast because of the presence of many suitable binding sites and larger surface area in the first $15 \mathrm{~min}$. The adsorption proceeds slowly after 15 min. due to the decrease of the binding sites, and the biosorption equilibrium occurred within $60 \mathrm{~min}$. After this equilibrium time, the amount of biosorbed cadmium ions did not significantly change with time.

\section{Adsorption Isotherms}

The isotherms data were characterized by the Langmuir and Freundlich equations. Linear form of the Langmuir and Freundlich isotherms is given by Eqs. (1) and (2), respectively:

$$
\begin{aligned}
& \frac{1}{q_{e}}=\frac{1}{q_{m}}+\frac{1}{K_{L} \cdot q_{m}} \cdot \frac{1}{C_{e}} \\
& \log q_{e}=\log K_{f}+\frac{1}{n} \log C_{e}
\end{aligned}
$$

...where $q_{\mathrm{m}}$ is maximum adsorption capacity $(\mathrm{mg} / \mathrm{g})$ and $K_{\mathrm{L}}$ is the Langmuir constant $(\mathrm{L} / \mathrm{mg})$. When $1 / q_{\mathrm{e}}$ was plotted against $1 / C$ e, the values of $q_{\mathrm{m}}$ and $K_{L}$ were obtained from the slope and intercept of the fitted line, respectively. $K_{f}$ and $\mathrm{n}$ are the Freundlich constants. These parameters can be determined from the plot of $\log q_{\mathrm{e}} \mathrm{vs}$. $\log C$ e. In this study, the Langmuir and Freundlich models were applied to describe the equilibrium isotherms at different temperatures $\left(15-45^{\circ} \mathrm{C}\right)$. The biosorption isotherms are presented in Table 1. Comparing the $\mathrm{R}^{2}$ values between Freundlich and Langmuir models, the Langmuir equation has better values for the adsorption of $\mathrm{Cd}$ (II) than the Freundlich equation at all temperature values. According to the obtained data, the biosorption process followed the Langmuir adsorption isotherms model with high coefficients of correlation at different temperatures $\left(\mathrm{R}^{2}>0.99\right)$. The maximum biosorption capacity $q_{m}$ for $\mathrm{Cd}(\mathrm{II})$ at $45^{\circ} \mathrm{C}$ was obtained as $3.915 \mathrm{mg} / \mathrm{g}$.

\section{Adsorption Kinetics}

Knowledge of the kinetics of any biosorption process is crucial in order to explain the sorption mechanisms. The kinetic characteristics of adsorption process were described by pseudo first-order rate Eq. (3) and pseudo second-order equation Eq. (4):

$$
\begin{gathered}
\log \left(q_{e}-q_{t}\right)=\log q_{e}-\left(\frac{\mathrm{k}_{1}}{2.303}\right) \cdot t \\
\frac{t}{q_{t}}=\frac{1}{k_{2}\left(q_{e}\right)^{2}}+\frac{t}{q_{e}}
\end{gathered}
$$

...where $t$ is the contact time (min); $k_{1}$ is the firstorder adsorption rate constant $\left(\mathrm{min}^{-1}\right)$, and $q_{\mathrm{e}}$ and $q_{t}$ are adsorption capacity at equilibrium and time $t$, respectively $(\mathrm{mg} / \mathrm{g})$. When $\log \left(q_{e}-q\right)$ was plotted against $\mathrm{t}$, the values of $q_{\mathrm{e}}$ and $k_{1}$ were obtained from the slope and intercept of the fitted line, respectively. $k_{2}$ is the secondorder adsorption rate constant $(\mathrm{g} / \mathrm{mg} \mathrm{min})$. When $t / q_{t}$ was plotted against $\mathrm{t}$, the values $q_{\mathrm{e}}$ and $k_{2}$ were determined from the slope and intercept of the plot, respectively. Finally, initial sorption rate Eq. (5) is:

$$
h=k_{2}\left(q_{e}\right)^{2}
$$

...where $h$ is the initial sorption rate $(\mathrm{mg} / \mathrm{g} \mathrm{min})$. The kinetic studies were applied at $15^{\circ} \mathrm{C}, 25^{\circ} \mathrm{C}$, and $45^{\circ} \mathrm{C}$, and the results are shown in Table 2 and Fig. 6 (a-b).

Table 1. Langmuir and Freundlich isotherm parameters for the biosorption of Cd(II).

\begin{tabular}{|c|c|c|c|c|c|c|}
\hline \multicolumn{4}{|c|}{ Freundlich Isotherms } & \multicolumn{3}{c|}{ Langmuir Isotherms } \\
\hline $\mathrm{T}\left({ }^{\circ} \mathrm{C}\right)$ & $\mathrm{K}_{\mathrm{f}}$ & $\mathrm{n}$ & $\mathrm{R}^{2}$ & $q_{m,}(\mathrm{mg} / \mathrm{g})$ & $\mathrm{K}_{\mathrm{L}},(\mathrm{L} / \mathrm{mg})$ & $\mathrm{R}^{2}$ \\
\hline 15 & 1.553 & 2.554 & 0.932 & 2.672 & 1.941 & 0.999 \\
\hline 25 & 1.726 & 2.320 & 0.975 & 3.508 & 1.501 & 0.995 \\
\hline 45 & 1.904 & 2.359 & 0.962 & 3.915 & 1.589 & 0.991 \\
\hline
\end{tabular}


Table 2. Kinetic parameters for biosorption of Cd(II).

\begin{tabular}{|c|c|c|c|c|c|c|c|c|}
\hline \multirow{2}{*}{$\mathrm{T}\left({ }^{\circ} \mathrm{C}\right)$} & \multicolumn{4}{|c|}{ Pseudo first-order } & \multicolumn{5}{c|}{ Pseudo- second order } \\
\cline { 2 - 10 } & $q_{e, \text { exp }}$ & $\mathrm{k}_{1}(1 / \mathrm{min})$ & $q_{e, \text { cal }}(\mathrm{mg} / \mathrm{g})$ & $\mathrm{R}^{2}$ & $q_{e, \text { cal }}(\mathrm{mg} / \mathrm{g})$ & $\mathrm{k}_{2}(\mathrm{~g} / \mathrm{mg} \min )$ & $\mathrm{h}(\mathrm{mg} / \mathrm{g}$ min $)$ & $\mathrm{R}^{2}$ \\
\hline 15 & 3.680 & 0.024 & 1.073 & 0.705 & 3.805 & 0.107 & 1.549 & 0.999 \\
\hline 25 & 3.910 & 0.020 & 0.852 & 0.570 & 3.962 & 0.114 & 1.785 & 0.999 \\
\hline 45 & 3.950 & 0.032 & 1.074 & 0.820 & 4.031 & 0.125 & 2.035 & 0.999 \\
\hline
\end{tabular}

In the pseudo second-order kinetic model, the $\mathrm{R}^{2}$ value was found to be higher than the pseudo first-order model. Also $q_{e, c a l}$ and $q_{e, e x p}$ values are found to be closer in the pseudo second-order model. This indicates that the pseudo second-order model is more suitable for biosorption of $\mathrm{Cd}(\mathrm{II})$.

\section{Activation Energy}

Activation energy is determined according to the Arrhenius equation Eq. (6):
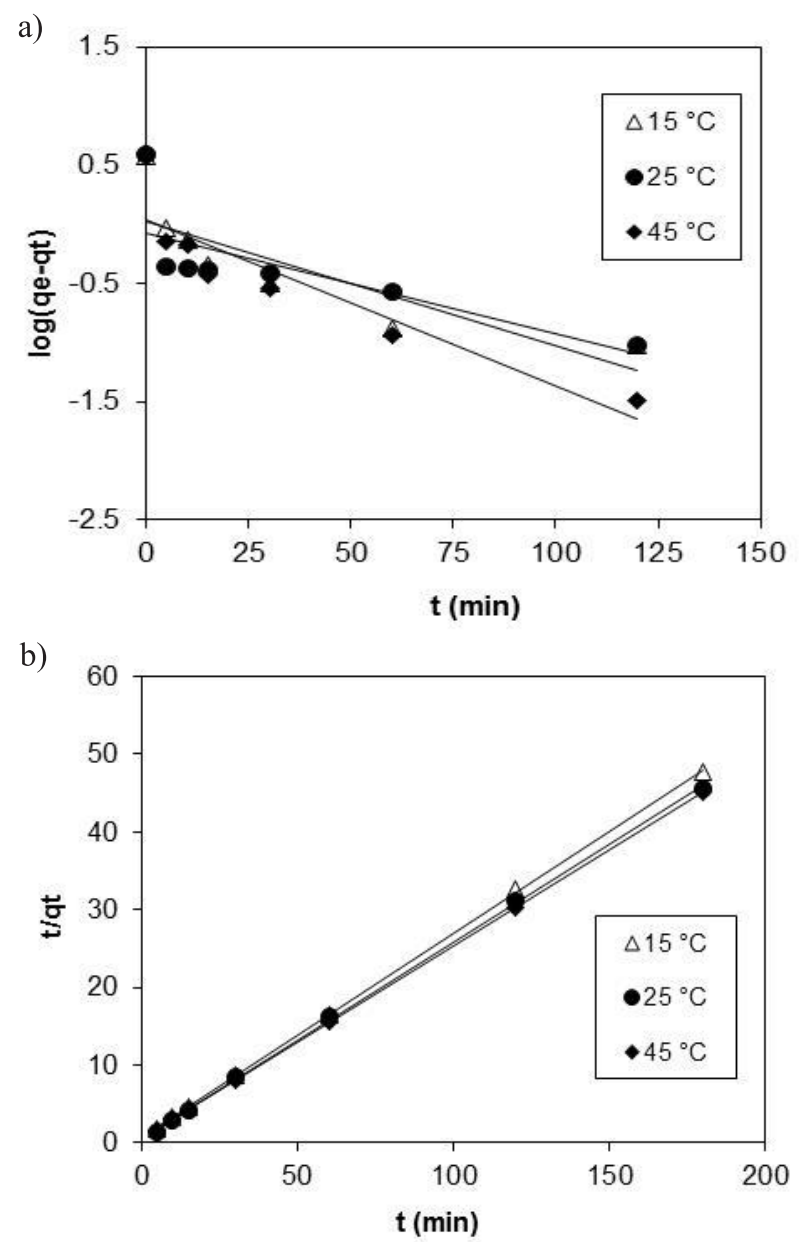

Fig. 6. Plots if biosorption kinetic equations: (a) pseudo firstorder and (b) pseudo second-order biosorption kinetics.

$$
\ln k=\left(\frac{-E_{a}}{R T}\right)+\ln A
$$

...where $E_{a}$ is activation energy, $T$ is temperature (Kelvin), $R$ is the gas constant $(8.314 \mathrm{~J} / \mathrm{mol} . \mathrm{K})$ and $A$ is a constant (frequency factor). $E_{a}$ was calculated from the slope of $\ln k$ versus $1 / T$ plot. In this study, activation energy for the biosorption of $\mathrm{Cd}(\mathrm{II})$ onto Uludag fir was determined. The results are presented in Fig. 7. The activation energy of biosorption $\left(E_{a}\right)$ and correlation coefficient $\left(\mathrm{R}^{2}\right)$ were found to be $3.984 \mathrm{~kJ} / \mathrm{mol}$ and 0.99 , respectively. According to the results, it can be said that biosorption of $\mathrm{Cd}(\mathrm{II})$ by Uludag fir is physisorption. There are two types of adsorption, including physical and chemical. The activation energy for physical adsorption is usually not more than $4.2 \mathrm{~kJ} / \mathrm{mol}$, since the forces involved in physical adsorption are weak. Chemical adsorption is specific and involves forces much stronger than in physical adsorption. Two kinds of chemical adsorption are encountered, activated and, less frequently, nonactivated. Activated chemical adsorption means that the rate varies with temperature according to a finite activation energy (between 8.4 and $83.7 \mathrm{~kJ} / \mathrm{mol}$ ) in the Arrhenius equation (high $E_{a}$ ). However, in some systems chemisorption occurs very rapidly, suggesting that the activation energy is near zero. This is termed non-activated chemisorption $[18,19]$.

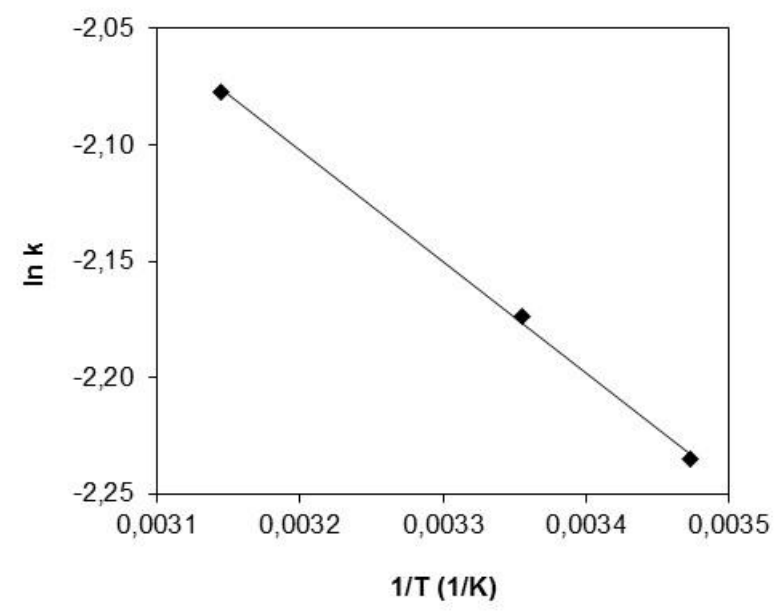

Fig. 7. Activation energy. 
Table 3. Thermodynamic parameters for the biosorption of $\mathrm{Cd}(\mathrm{II})$.

\begin{tabular}{|c|c|c|c|c|}
\hline \multirow{2}{*}{$\begin{array}{c}\Delta \mathrm{H}^{0} \\
(\mathrm{~kJ} / \mathrm{Kmol})\end{array}$} & \multirow{2}{*}{$\begin{array}{c}\Delta \mathrm{S}^{0} \\
(\mathrm{~J} / \mathrm{mol} \mathrm{K})\end{array}$} & \multicolumn{3}{|c|}{$\Delta \mathrm{G}^{0}(\mathrm{~kJ} / \mathrm{mol})$} \\
\cline { 3 - 5 } & & 15 & 25 & 45 \\
\hline 0.970 & 96.218 & -17.895 & -19.248 & -20.840 \\
\hline
\end{tabular}

\section{Thermodynamic Parameters}

Thermodynamic parameters of standard Gibbs free energy $\left(\Delta G^{\circ}\right)$, standard enthalpy $\left(\Delta H^{\circ}\right)$ and standard entropy $\left(\Delta S^{\circ}\right)$ were determined:

$$
\begin{gathered}
\ln K_{d}=\frac{\Delta S^{o}}{R}-\frac{\Delta H^{o}}{R T} \\
\Delta G^{o}=\Delta H^{o}-T \Delta S^{o} \\
K_{d}=\frac{q_{e}}{C_{e}}
\end{gathered}
$$

...where $K_{d}$ is the distribution coefficient for adsorption, $T(\mathrm{~K})$ is the temperature, and $\mathrm{R}\left(\mathrm{J} \cdot \mathrm{mol}^{-1} \cdot \mathrm{K}^{-I}\right)$ is the gas constant. The amounts of $\Delta H^{\circ}$ and $\Delta S^{\circ}$ could be calculated from the slope and intercept of the straight line obtained by plotting ln $K d$ against $1 / T$, respectively. Values of thermodynamic parameters should be taken into consideration in order to determine the spontaneity, feasibility and nature of the biosorption process. $[15,20]$. The values of $\Delta \mathrm{G}^{0}$, $\Delta H^{0}$, and $\Delta \mathrm{S}^{0}$ are presented in Table 3. In this study, negative $\Delta G^{0}$ values for all studied temperatures showed that the biosorption process was feasible and spontaneous. The positive value of $\Delta H^{0}(0.970 \mathrm{~kJ} / \mathrm{Kmol})$ indicated that the biosorption process is endothermic. Moreover, the positive value of $\Delta \mathrm{S}^{0}(96.218 \mathrm{~J} / \mathrm{mol} \mathrm{K})$ indicates the randomness at the biosorbent-solution interface.

\section{Conclusions}

The objective of this work was to evaluate the application of Uludag fir (Abies nordmanniana subsp. bornmülleriana Mattf.) as biosorbent for the removal of $\mathrm{Cd}(\mathrm{II})$ from aqueous solutions by batch biosorption experiments. The parameters, including initial $\mathrm{Cd}(\mathrm{II})$ concentrations, initial $\mathrm{pH}$, adsorbent dosage, stirring speed, temperature and contact time, were investigated. According to the results, the biosorption process was strongly affected by these parameters. Also, the Langmuir and Freundlich models were used to describe the equilibrium biosorption data of $\mathrm{Cd}(\mathrm{II})$ onto Uludag fir. The equilibrium data fits Langmuir adsorption isotherms model, and adsorption capacity was found to be $3.915 \mathrm{mg} / \mathrm{g}$ at optimized conditions. Adsorption kinetics of $\mathrm{Cd}(\mathrm{II})$ follow the pseudo second-order model. Thermodynamic parameters $\left(\Delta \mathrm{G}^{0}\right.$, $\left.\Delta \mathrm{H}^{0}, \Delta \mathrm{S}^{0}\right)$ also showed that the sorption process was feasible, spontaneous and endothermic in nature. The activation energy of biosorption $\left(E_{a}\right)$ and correlation coefficient $\left(\mathrm{R}^{2}\right)$ was found to be $3.984 \mathrm{~kJ} / \mathrm{mol}$ and 0.99 , respectively. The results obtained showed that this environmentally friendly, efficient and low-cost Uludag fir (Abies nordmanniana subsp. bornmülleriana Mattf.) as a biosorbent can be useful for the removal of $\mathrm{Cd}(\mathrm{II})$ from aqueous solutions.

\section{Acknowledgements}

The authors would like to thank Bartin University for the support of the foundation under project No. BAP 2017-FEN-A-001.

\section{Conflict of Interest}

The authors have not declared any conflict of interest.

\section{References}

1. HEGAZI H.A. Removal of heavy metals from wastewater using agricultural and industrial wastes as adsorbents. Housing and Building National Research Center, 9 (3), 276, 2013.

2. RATHORE N.S., LEOPOLD A., PABBY A.K., FORTUNY A., COLL M.T., SASTRE A.M. Extraction and permeation studies of $\mathrm{Cd}(\mathrm{II})$ in acidic and neutral chloride media using Cyanex 923 on supported liquid membrane. Hydrometallurgy, 96, 81, 2009.

3. WANG B., GAO B., WAN Y. Entrapment of ball-milled biochar in Ca-alginate beads for the removal of aqueous $\mathrm{Cd}(\mathrm{II})$. Journal of Industrial and Engineering Chemistry, 61, 161, 2018

4. CHENG Q., HUANG Q., KHAN S., LIU Y., LIAO Z., LI G., OK Y.S. Adsorption of Cd by peanut husks and peanut husk biochar from aqueous solutions. Journal of Ecological Engineering, 87, 240, 2016.

5. NGUYEN T.A.H., NGO H.H., GUO W.S., ZHANG J., LIANG S., YUE Q.Y., Li Q., NGUYEN T.V. Applicability of agricultural waste and biproducts for adsorptive removal of heavy metals from wastewater. Bioresource Technology, 148, 574, 2013.

6. KUMAR P.S., RAMAKRISHNAN K., KIRUPHA S.D., SIVANESAN S., Thermodynamic and kinetic studies of cadmium adsorption from aqueous solution onto rice husk. Brazilian Journal of Chemical Engineering, 27 (2), 347, 2010.

7. TU Y.J., YOU C.F., CHANG C.K. Kinetics and thermodynamics of adsorption for $\mathrm{Cd}$ on green manufactured nano-particles. Journal of Hazardous Materials, 235, 116, 2012.

8. CUTILLAS-BARREIRO L., PARADELO R., IGREXASSOTO A., NUNEZ-DELGADO A., FERNANDEZ- 
SANJURJO M.J., ALVAREZ-RODRIGUEZ E., GARROTE G., NOVOA-MUNOZ J.C., ARIAS-ESTEVEZ M. Valorization of biosorbent obtained from a forestry waste: Competitive adsorption, desorption and transport of $\mathrm{Cd}, \mathrm{Cu}, \mathrm{Ni}, \mathrm{Pb}$ and $\mathrm{Zn}$. Ecotoxicology and Environmental Safety, 131, 118, 2016.

9. BOZIC D., STANKOVIC V., GORGIEVSKI M., BOGDANOVIC, G., KOVACEVIC R. Adsorption of heavy metal ions by sawdust of deciduous trees. Journal of Hazardous Materials, 171, 684, 2009.

10. OFOMAJA A.E., NAIDOO E.B., MODISE S.J., Biosorption of $\mathrm{Cu}(\mathrm{II})$ and $\mathrm{Pb}(\mathrm{II})$ onto potassium hydroxide treated pine cone powder. Journal of Environmental Management, 91, 1674, 2010.

11. SEN T.K., MOHAMMOD M., MAITRA S., DUTTA B.K. Removal of cadmium from aqueous solution using castor seed hull: a kinetic and equilibrium study. Clean-Soil, Air, Water, 38, 850, 2010.

12. KUMAR P.S., RAMALINGAM S., SATHYASELVABALA V., KIRUPHA S.D., MURUGESAN A., SIVANESAN S. Removal of Cd(II) from aqueous solution by agricultural waste cashew nut shell. Korean Journal of Chemical Engineering, 29, 756, 2012.

13. FAROOQ U., KHAN M.A., ATHAR M., KOZINSKI J.A. Effect of modification of environmentally friendly biosorbent wheat (Triticum aestivum) on the biosorptive removal of cadmium(II) ions from aqueous solution. Chemical Engineering Journal, 171, 400, 2011.

14. KIM N., PARK M., PARK D. A new efficient forest biowaste as biosorbent for removal of cationic heavy metals. Bioresource Technology, 175, 629, 2015.

15. UCUN H., AKSAKAL O., YILDIZ E. Copper(II) and zinc(II) biosorption on Pinus sylvestris L. Journal of Hazardous Materials, 161, 1040, 2009.

16. CHEN Y., WANG H., ZHAO W., HUANG S. Four different kinds of peels as adsorbents for the removal of Cd (II) from aqueous solution: Kinetics, isotherm and mechanism. Journal of the Taiwan Institute of Chemical Engineers, 88, 146, 2018.

17. KULKARNI M.R., REVANTH T., ACHARYA A., BHAT P. Removal of crystal violet dye from aqueous solution using water hyacinth: equilibrium, kinetics and thermodynamics study. Resource-Efficient Technologies, 3, 71, 2017.

18. SMITH J.M. Chemical Engineering Kinetics, $3^{\text {rd }}$ ed.; McGraw-Hill: New York, USA, 310, 1981.

19. UCUN-OZEL H. Biosorption of Cd(II) ions by Nordmann fir cones. Fresenius Environmental Bulletin, 21 (9), 2527, 2012.

20. DENIZ F., KEPEKCI R.A. Bioremoval of malachite green from water sample by forestry waste mixture as potential biosorbent. Microchemical Journal, 132, 172, 2017. 
